\title{
An Analysis of an Organisational Strategy, Structure and Culture that Supports Corporate ENTREPRENEURShIP in Established Organisations
}

\author{
T Nayager \\ Department of Business Management, University of South Africa \\ J J van Vuuren \\ Department of Business Management, University of Pretoria
}

\begin{abstract}
The environment in which a business operates is not static. Intensifying global competition and rapid technological progress put pressure on business to change. Better quality and service and lower costs are no longer enough to give a competitive advantage. Adaptability, flexibility, speed, aggressiveness and innovativeness are increasingly necessary. This can be achieved by entrepreneurial organisations. Through corporate entrepreneurship, big business can improve its profitability and competitive standing. This research aims to determine the characteristics of organisational strategy, structure and culture that foster corporate entrepreneurship in large and established companies. These characteristics were applied to an established organisation to evaluate to what extent its strategy, culture and structure would support entrepreneurial activities and initiatives. Data were collected through self-completion questionnaires and analysed by calculating Cronbach alpha values, t-test and ANOVA.
\end{abstract}

Abstract

JEL M13, 14

\section{1 \\ Introduction}

The environment in which a business operates is not static. In fact the rate of change has been ever accelerating over the past two decades. Intensifying global competition and rapid technological progress are characteristics of the business environment today. A sustainable competitive advantage can only be achieved through continuous innovation and the creation of new ideas (Morris \& Kuratko, 2002: vii). Organisations need to develop new and improved products and services, as well as better operating technology and methods that are more effective than those of competitors, to ensure a competitive advantage and market dominance. Rather than compete with competitors head on, businesses should focus on developing new products and services and new markets, but this can only be achieved by organisations that adopt an entrepreneurial orientation.

2

Objective

The primary objective of the study is to determine the characteristics of organisational strategy, structure and culture that foster corporate entrepreneurship in large and established companies, and to apply these characteristics to an existing organisation to evaluate to what extent its strategy, culture and structure support entrepreneurial initiatives.

The result is that an organisation would know whether its internal environment is conducive to being entrepreneurial, and how it should be improved in order to become entrepreneurial. 
3

\section{Corporate entrepreneurship}

According to Pinchot (1985: vii), corporate entrepreneurship is entrepreneurship within an established business organisation. Sharma and Chrisman (1999: 11) and Geisler (1993: 53) define corporate entrepreneurship as the process whereby an individual or group of individuals in association with an established company creates a new organisation, or instigates renewal or innovation within the current organisation.

Corporate entrepreneurship revitalises, reinvigorates and reinvents. It is the spark and catalyst that is intended to place firms on the path to competitive superiority or keep them in a competitively advantageous position. Empirical research from former studies supports the notion that corporate entrepreneurship improves company performance by making the firm more proactive and more willing to take risks and by pioneering the development of new products, processes and services (Covin, 1991; Kuratko, Montagno \& Hornsby, 1990; Lumpkin \& Dess, 1996; Zahra, Covin \& Zahra, 1998 and Zahra \& Pearce, 1989).

Hardware, people and software as described by Dess, Lumpkin and McKee (1999: 85) are interrelated concepts and capture the salient attributes inherent in corporate entrepreneurship. There must be a good fit among the three components (hardware, people and software) in the organisation's architecture before strategic renewal and innovation could be brought about (Dess, Lumpkin \& McKee, 1999: 85). Hardware refers to the organisational structure, business planning systems, control mechanisms and reporting relationships; people refers to skills, personality and character of employees; and software refers to informal networks and practices, value systems and culture.

\subsection{Developing corporate entrepreneurship}

Figure 1 illustrates the perspective that entrepreneurship is an overall orientation in an organisation. The focus here is on the integration of entrepreneurship throughout the entire organisation, as opposed to viewing entrepreneurship as a discrete activity or behaviour or once-off event (Morris \& Kuratko, 2002: 33). The model illustrates that entrepreneurial intensity has a direct and positive influence on company performance. It does this by integrating or interweaving the vision and mission of the firm, the strategies, objectives and structures of the organisation and the overall organisational culture (Morris \& Kuratko, 2002: 34).

Figure 1

Integration of entrepreneurship throughout the organisation

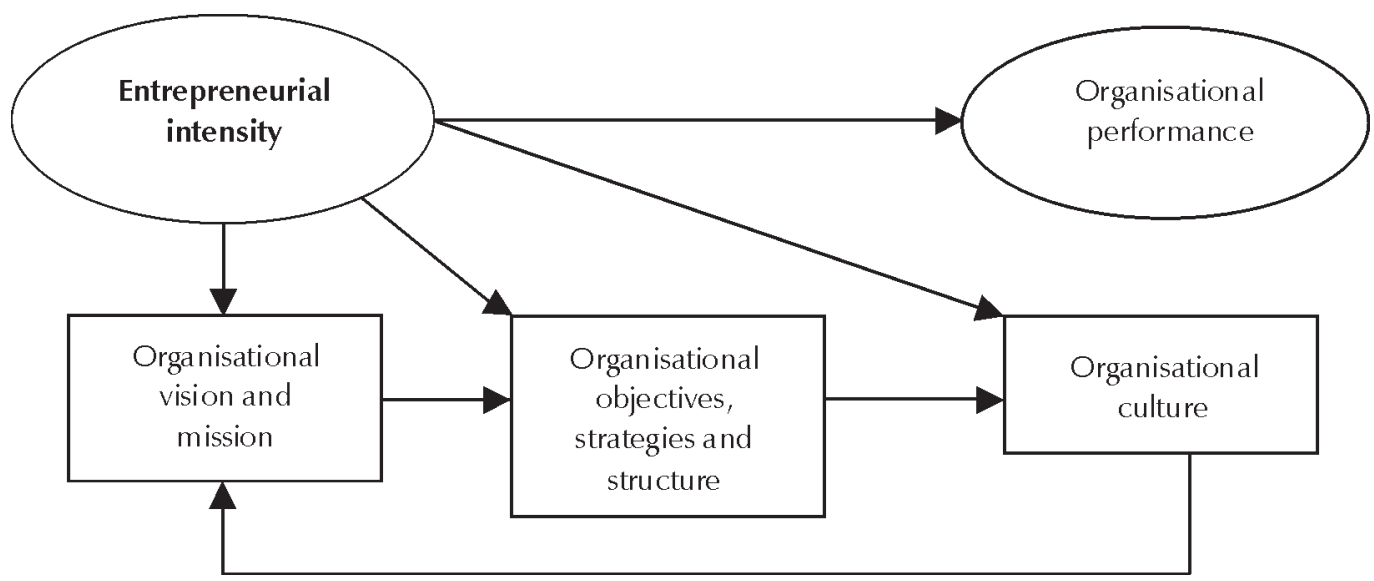

Adapted from Morris and Kuratko (2002: 34) 
There is a link between strategy, structure and culture and organisational performance. The individual blocks serve to illustrate the individual elements of creating an entrepreneurial orientation and to allow for managerial intervention at each level or stage. The overall objective of the model is the revitalisation of creativity, product and process innovation and ongoing managerial development. If organisational entrepreneurship is seen as behaviour that consists of different components, managers can manage and control entrepreneurship.

\subsection{Entrepreneurial strategy}

According to Russel and Russel (1992: 640), entrepreneurial strategy is the component of corporate strategy that promotes the persistent search for competitive advantage through innovation. These efforts may comprise a firm's main strategic thrust, or may be a minor element of a broader grand strategy.

Strategy is formulated by top management, and not much can be achieved in terms of entrepreneurship if there is little direction from top management. Without specific goals and strategies for innovation, entrepreneurship in the business will happen by chance or haphazardly. There has to be commitment from senior managers to create entrepreneurship in the business.

A clear, challenging and well-known entrepreneurial vision and strategy bring forth a large volume of well-aligned innovation (Pinchot, 1985: 15). This is because vision and strategy create a sense of unity or consistency of action throughout an organisation. In order for people to work toward common objectives, the objectives of the company must be imparted to them. Therefore the presence of corporate entrepreneurship creates opportunities to be innovative and more dynamic, even though it exposes the organisation to risk. If employees do not have a strong understanding that innovation is the firm's ultimate aim, then their daily actions will not support innovative endeavours. As they make choices in their jobs, strategy can provide direction to these choices (Morris \& Kuratko, 2002: 154).

\subsection{Entrepreneurial structure}

Organisations can be characterised by the degree to which they have an organic or a mechanistic organisational structure (Covin \& Selvin, 1991: 44). An organic organisation is more openly communicative, more consensual and more loosely controlled (a flat structure), while a mechanistic organisation tends to be more traditional, tightly controlled and hierarchical in its approach.

In research conducted by Selvin and Covin (1990: 44), an entrepreneurial firm's behaviour correlates positively with firm performance in the presence of an organic organisational structure, while it correlates negatively with firm performance in the presence of a mechanistic organisational structure.

Organisational structure needs to be flexible enough to respond quickly to changes in the environment and facilitate communication of these changes, enable efficient and effective communication between members of the entrepreneurial team and between employees in all departments. Structure should also ensure delegation of responsibility and authority over work to enable employees to be creative and solve problems.

Team members must be able to span functional boundaries within the organisation to form project teams that can develop new product ideas.

\subsection{Entrepreneurial culture}

Culture is a system of shared meaning held by members that distinguishes the organisation from other organisations. Culture serves as a control mechanism that guides and shapes the attitudes and behaviours of employees. Culture allows organisations to develop a core set of assumptions, understandings and implicit rules that govern day-to-day behaviour in the workplace (Robbins, 2001: 510). The shared meaning provided by strong culture ensures that everyone is working in the same direction. Corporate entrepreneurship can be sustained in the organisation if it is embedded in the culture of the organisation.

Entrepreneurial culture should encourage employees to be creative and innovative, to 
experiment with new products, to make suggestions for the improvement of products and internal processes, to take risks, responsibility and ownership of their creations.

The above can only happen if management allows employees to take risks, make mistakes and fail in their attempts at innovation, if management supports employees in their entrepreneurial initiatives, if employees have the authority to do their job and be responsible in their work, if employees are rewarded for being innovative, are given resources to develop their innovation and are allowed flexibility and time in developing their innovation.

According to Hornsby et al. (1993: 29), Kuratko, Montagno and Hornsby (1990: 49) and Hisrich and Peters (1998: 47), organisational characteristics that foster corporate entrepreneurship are: rewards for innovation, management support of entrepreneurial projects, resource availability, risk-taking, and a tolerance of failure. Management has control of each of the abovementioned elements.

\section{4}

\section{Research methodology}

This quantitative research study makes use of an exploratory research design, as its intention is to determine whether or not a phenomenon exists. A case study design was also used because an established organisation with 70 staff members was studied. The 70 staff members of the organisation comprise the population and sample of the study. Non-probability purposive sampling was used to select sample members because it was the intention to get most if not all employees to participate in the study, but not all were available. The organisation was selected randomly.

The entrepreneurial climate questionnaire developed by Gifford Pinchot III was used to determine the entrepreneurial climate in this organisation. The measuring instrument used a five-point Likert scale with options that range from strongly agree to strongly disagree.

A pilot study was conducted to achieve an acceptable level of face validity which served as a basis to continue with the data collection. Five respondents chosen at random were interviewed for the pilot study. As a result of the pilot study, some of the questions or statements were rephrased or edited to make them more understandable without changing the meaning of the question/statement and negatively influencing the validity and reliability of the measuring instrument.

Self-completion questionnaires were handed to the 70 staff members. Fifty one questionnaires were returned, achieving a response rate of 76 per cent. Data obtained were captured as interval or ratio data using the SPSS software package to execute the analysis.

The statistical analysis comprised descriptive statistics such as frequency, mean and standard deviation and inferential statistics such as statistical significance, analysis of variance and t-tests. The study made use of internal reliability consistency by calculating the Cronbach Alpha coefficients.

\section{5}

\section{Research results}

The measuring instrument was divided into different sub-dimensions or constructs of entrepreneurial climate. The entrepreneurial climate was measured by the following eight constructs:

- Transmission of vision and strategic intent

- Tolerance of risk, mistakes and failure

- Support for corporate entrepreneurs

- Empowered cross-functional teams

- Self-selection as entrepreneurs

- Strong organisational community in the organisation

- Transparency and truth amongst employees and

- Good treatment of employees in the organisation.

Given the above, the following hypotheses were to be tested:

Hypothesis 1 Ho: Transmission of vision and strategic intent 
Ha: No transmission of the vision and strategic intent

Hypothesis 2 Ho: Risks, mistakes and failure are tolerated

Ha: Risks, mistakes and failure are not tolerated

Hypothesis 3 Ho: Entrepreneurs are supported

Ha: There is little support for entrepreneurs

Hypothesis 4 Ho: Empowered cross-functional teams exist

Ha: Few or no empowered cross-functional teams exist

Hypothesis 5 Ho: Entrepreneurs are selfselected (they choose to innovate and be part of entrepreneurial teams)

\subsection{Internal reliability consistency}

Cronbach's Alpha coefficients were calculated for each of the constructs, as well as the Cronbach's Alpha values if any particular item were to be deleted from the construct. This enabled the researcher to exclude some items
Ha: No self-selection exists (entrepreneurs are appointed to teams and projects)

Hypothesis 6 Ho: A strong organisational community has been established

Ha: No organisational community has been established

Hypothesis 7 Ho: Truth and transparency are present

Ha: No truth and transparency exist within the organisation

Hypothesis 8 Ho: People are treated well consistently

Ha: People are not treated well on a consistent basis.

from the analysis, which, by their exclusion, improved the internal reliability consistency of the construct. The generally-agreed lower limit for the Cronbach Alpha coefficient is 0.70, although the requirement may be lowered to 0.60 in the case of exploratory research (Hair et al., 1998: 118).

Table 1

The Cronbach Alpha Coefficients for each construct after exclusion of some items

\begin{tabular}{|c|l|c|c|}
\hline $\mathbf{N}^{\circ}$. & Construct & $\begin{array}{c}\text { Number of items } \\
\text { per construct }\end{array}$ & $\begin{array}{c}\text { Cronbach Alpha } \\
\text { coefficients }\end{array}$ \\
\hline 1 & Transmission of vision and strategic intent & 6 & 0.815 \\
\hline 2 & Tolerance of risk, mistakes and failure & 3 & 0.740 \\
\hline 3 & Support for corporate entrepreneurs & 9 & 0.780 \\
\hline 4 & Empowered cross-functional teams & 4 & 0.402 \\
\hline 5 & Self-selection & 6 & 0.557 \\
\hline 6 & Strong organisational community & 5 & 0.642 \\
\hline 7 & Transparency and truth & 4 & 0.721 \\
\hline 8 & Good treatment of people & 4 & 0.740 \\
\hline
\end{tabular}

It can be deduced from Table 1 that the constructs empowered cross-functional teams, and self-selection may have contributed to a lower level of accuracy among some of the other constructs, for example, strong organisational community. It was, however, decided to continue with the constructs because of the contribution to results possibly obtained later in the analysis.

\subsection{Corporate entrepreneurial profile of the organisation}

The profile of the organisation in terms of the identified constructs is illustrated in Table 2 (see Figure 2). 
Table 2

Means and standard deviations of the corporate entrepreneurship factors ( $n=51$ )

\begin{tabular}{|l|c|c|c|c|}
\hline & Minimum & Maximum & Mean & Std deviation \\
\hline VISION & 1.33 & 4.83 & 3.26 & 0.690 \\
\hline RISK & 1.00 & 4.50 & 2.99 & 0.822 \\
\hline EMPOW & 1.00 & 4.00 & 2.79 & 0.589 \\
\hline SELF & 2.00 & 3.83 & 3.01 & 0.440 \\
\hline STRONG & 2.00 & 4.67 & 3.51 & 0.598 \\
\hline TRUTH & 1.00 & 4.25 & 3.14 & 0.725 \\
\hline GOOD & 1.00 & 4.25 & 3.37 & 0.785 \\
\hline SUPPORT & 1.56 & 4.00 & 3.00 & 0.629 \\
\hline
\end{tabular}

It can be deduced from Table 2 that although the level of deviation amongst the constructs is not high, that the means (on a scale of 1 to 5) are fairly high in terms of rangers (maximum minus minimum scores).

Figure 2

Graphic presentation of mean scores on the corporate entrepreneurship constructs

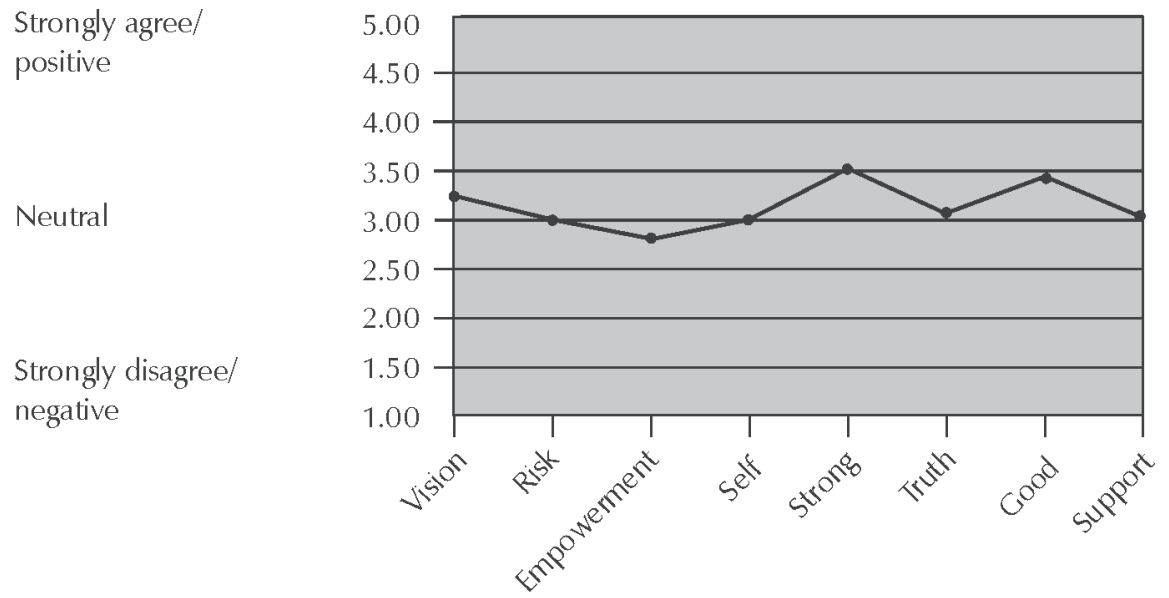

The organisation appears relatively lower on the empowering cross-functional teams and higher on transmission of vision and strategic intent, strong organisational community, transparency and truth, as well as good treatment of people factors. The staff feels fairly neutral or indifferent concerning risk tolerance, self-selection and support for entrepreneurs.

Further exploration regarding the data set needed to be conducted and based on the needs of the organisation; two independent variables, gender and age, were included.

\subsection{Comparison of males and females with regard to their perception of corporate entrepreneurship}

From Table 3 it is evident that the differences between the genders are not statistically significant at a 95 per cent confidence level. It is interesting to note that standard deviations on the issues of transmission of vision, risktaking, transparency and truth and empowerment show the greatest difference between males and females. The standard deviations of 
males were particularly high for these constructs, indicating that there is a wide spread around the mean and therefore a wide spread of opinions on these matters.

\section{Table 3}

Comparison of males and females on the corporate entrepreneurship factors: t-test

\begin{tabular}{|c|c|c|c|c|c|c|}
\hline & Gender & $\mathbf{N}$ & Mean & Std deviation & t-value & p-value \\
\hline \multirow[t]{2}{*}{ VISION } & Male & 21 & 3.04 & 0.807 & -1.90369 & 0.063 \\
\hline & Female & 30 & 3.41 & 0.562 & & \\
\hline \multirow[t]{2}{*}{ RISK } & Male & 21 & 3.13 & 1.072 & 1.052857 & 0.298 \\
\hline & Female & 30 & 2.89 & 0.589 & & \\
\hline \multirow[t]{2}{*}{ EMPOW } & Male & 21 & 2.73 & 0.733 & -0.68556 & 0.496 \\
\hline & Female & 30 & 2.84 & 0.471 & & \\
\hline \multirow[t]{2}{*}{ SELF } & Male & 21 & 3.04 & 0.492 & 0.459213 & 0.648 \\
\hline & Female & 30 & 2.98 & 0.407 & & \\
\hline \multirow[t]{2}{*}{ STRONG } & Male & 21 & 3.36 & 0.580 & -1.58117 & 0.120 \\
\hline & Female & 30 & 3.62 & 0.595 & & \\
\hline \multirow[t]{2}{*}{ TRUTH } & Male & 21 & 3.15 & 0.893 & 0.102848 & 0.919 \\
\hline & Female & 30 & 3.13 & 0.597 & & \\
\hline \multirow[t]{2}{*}{ GOOD } & Male & 21 & 3.27 & 0.908 & -0.71089 & 0.481 \\
\hline & Female & 30 & 3.43 & 0.695 & & \\
\hline \multirow[t]{2}{*}{ SUPPORT } & Male & 21 & 3.00 & 0.646 & 0.027112 & 0.978 \\
\hline & Female & 30 & 2.99 & 0.629 & & \\
\hline
\end{tabular}

Women feel more strongly than their male counterparts about their awareness of the vision and strategic intent, that a strong organisational community exists and that people are treated well. More men believe that the organisation has a higher tolerance of risks, mistakes and failure. The findings in Table 2 create the background to which these results are to be seen.

\subsection{Comparison of different age groups with regard to their perception of corporate entrepreneurship}

Persons of different age groups do not differ significantly with regard to their scores on corporate entrepreneurship factors, as can be seen from Table 4.

\section{Table 4}

Comparing age groups' views on corporate entrepreneurship factors (ANOVA)

\begin{tabular}{|l|l|c|c|c|c|c|}
\hline & & $\mathbf{N}$ & Mean & Std deviation & f-value & p-value \\
\hline VISION & $20-30$ years & 17 & 3.16 & 0.691 & 0.822 & 0.488 \\
\hline & $31-40$ years & 16 & 3.33 & 0.613 & & \\
\hline & $41-50$ years & 7 & 3.57 & 0.999 & & \\
\hline RISK & 50 and above & 11 & 3.11 & 0.579 & & 0.825 \\
\hline & $20-30$ years & 17 & 3.04 & 0.655 & 0.300 & \\
\hline
\end{tabular}




\begin{tabular}{|c|c|c|c|c|c|c|}
\hline & $41-50$ years & 7 & 2.71 & 0.848 & & \\
\hline & 50 and above & 11 & 3.00 & 1.164 & & \\
\hline \multirow[t]{4}{*}{ EMPOW } & 20-30 years & 17 & 2.81 & 0.527 & 0.918 & 0.440 \\
\hline & $31-40$ years & 16 & 2.89 & 0.438 & & \\
\hline & $41-50$ years & 7 & 2.93 & 0.800 & & \\
\hline & 50 and above & 11 & 2.55 & 0.723 & & \\
\hline \multirow[t]{4}{*}{ SELF } & 20-30 years & 17 & 2.99 & 0.454 & 0.035 & 0.991 \\
\hline & $31-40$ years & 16 & 3.02 & 0.452 & & \\
\hline & $41-50$ years & 7 & 2.98 & 0.353 & & \\
\hline & 50 and above & 11 & 3.03 & 0.505 & & \\
\hline \multirow[t]{4}{*}{ STRONG } & 20-30 years & 17 & 3.62 & 0.564 & 0.635 & 0.596 \\
\hline & $31-40$ years & 16 & 3.55 & 0.626 & & \\
\hline & $41-50$ years & 7 & 3.50 & 0.518 & & \\
\hline & 50 and above & 11 & 3.30 & 0.678 & & \\
\hline \multirow[t]{4}{*}{ TRUTH } & 20-30 years & 17 & 3.32 & 0.550 & 0.525 & 0.667 \\
\hline & $31-40$ years & 16 & 3.06 & 0.809 & & \\
\hline & $41-50$ years & 7 & 3.07 & 1.018 & & \\
\hline & 50 and above & 11 & 3.02 & 0.675 & & \\
\hline \multirow[t]{4}{*}{ GOOD } & 20-30 years & 17 & 3.46 & 0.725 & 0.344 & 0.794 \\
\hline & $31-40$ years & 16 & 3.34 & 0.730 & & \\
\hline & 41-50 years & 7 & 3.11 & 1.257 & & \\
\hline & 50 and above & 11 & 3.43 & 0.653 & & \\
\hline \multirow[t]{4}{*}{ SUPPORT } & 20-30 years & 17 & 2.96 & 0.588 & 1.409 & 0.252 \\
\hline & $31-40$ years & 16 & 3.11 & 0.523 & & \\
\hline & $41-50$ years & 7 & 3.26 & 0.527 & & \\
\hline & 50 and above & 11 & 2.71 & 0.829 & & \\
\hline
\end{tabular}

Again, even though not statistically significant, it is interesting to note that in terms of support for entrepreneurs, the different age groups felt differently about whether the organisation supports entrepreneurs or not. The older age groups, that is, 41 to 50 and 50 and above, have higher standard deviations than the younger age groups, that is, 20 to 30 and 31 to 40 . This indicates that there is a wide spread around the mean, and therefore a wide spread of opinions on these matters.

\section{6 \\ Research results}

Hypothesis 1: Transmission of vision and strategic intent of the organisation

The null hypothesis is accepted. A transmission of the vision and strategic intent to members of staff exists. The staff are aware of the vision and strategic intent and may take appropriate decisions and actions to pursue the vision and strategic intent. 
Hypothesis 2: Risks, mistakes and failure

The null hypothesis is rejected. Staff are neutral or indifferent to this measure of entrepreneurship. It was apparent from interviews conducted in the pilot study that respondents answered neither agree nor disagree, where they had no exposure or experience of the situation at hand. It is for this reason that the authors feel that wherever there was a central tendency, the entrepreneurial factor was not present. The organisation should be tolerant of risks, mistakes and failure.

\section{Hypothesis 3: Support for entrepreneurs}

The null hypothesis is rejected. Staff are neutral or indifferent to this measure of entrepreneurship. It was apparent from interviews conducted in the pilot study that respondents answered neither agree nor disagree, where they had no exposure or experience of the situation being measured. It is for this reason that the authors instigate that where there was a central tendency, the entrepreneurial factor was not present. The organisation needs to be more supportive of entrepreneurs by creating an environment conducive to entrepreneurship.

\section{Hypothesis 4: Empowered cross-functional teams}

The null hypothesis is rejected. A few empowered cross-functional teams are present or departments do not use teams effectively. The organisation needs to pay attention to the optimal utilisation of teams.

\section{Hypothesis 5: Self-selection}

The null hypothesis is rejected. Staff are neutral or indifferent to this measure of entrepreneurship. As mentioned above, where there is a central tendency, the entrepreneurial factor does not exist. The organisation needs to give attention to the self-selection of entrepreneurs. Entrepreneurial behaviour and joining teams should be voluntary.

Hypothesis 6: Strong organisational community The null hypothesis is accepted. This can be deduced from the fact that staff feel a sense of camaraderie and organisational community in the organisation and that they are willing to contribute to the success of the organisation. Staff are also willing to help each other.

\section{Hypothesis 7: Truth and transparency}

The null hypothesis is accepted. There is truth and transparency amongst staff members. Staff members communicate with each other and share information willingly.

\section{Hypothesis 8: Good treatment of people}

The null hypothesis is accepted. Staff feel that they are treated well. There is respect amongst staff members and a concern for staff as people.

\section{7}

\section{Limitations of the study}

The research study merely looked at the entrepreneurial climate of one organisation. The research did not correlate the entrepreneurial climate of the organisation to their level of corporate entrepreneurship, that is, the number of new innovations or other entrepreneurial initiatives.

\section{8}

\section{Management implications and conclusion}

The environment in which business operates has become increasingly dynamic and competitive. Managers have adopted many different management tools and techniques to achieve competitive advantage. The only way an organisation can achieve sustainable competitive advantage is if they continue to be innovative, i.e. they create new and improved products, services and processes (Morris \& Kuratko, 2002: 10).

In order to create innovation, the organisation has to have an internal environment or orientation that supports entrepreneurship. Their strategies, structure, systems, policies and procedures and managers should therefore support innovation and corporate entrepreneurship. If managers understood or knew how their organisations were performing in the various facets of entrepreneurial orientation, they would know where to make improvements.

Companies that create an environment conducive to corporate entrepreneurship and implements new innovations and innovative 
ideas for improvement within the company will reap the benefits of increased profitability, organisational learning and knowledge creation. An organisation that experiments with the creation of new products, creates knowledge and utilises that knowledge, perpetuates its growth.

This article deals with the challenge facing most companies in this country. Corporate entrepreneurship is introduced as a vehicle to improve profitability and competitiveness of companies.

It is hoped that the article will stimulate thinking into reviewing management practices and strategies and introducing corporate entrepreneurship into large organisations to facilitate growth.

In this study it was found that the organisation investigated should be more tolerant of failure, allow employees to take some risks, support entrepreneurs and use teams more effectively.

\section{References}

1 COVIN, J.G. (1991) "Entrepreneurial versus conservative firms: A comparison of strategies and performance", Journal of Management studies, 28: 439-62.

2 COVIN, J.G. \& SELVIN, D.P. (1991) “A conceptual model of entrepreneurship as firm behavior', Entrepreneurship: Theory and Practice, 16(1): 7-25.

3 DESS, G.G.; LUMPKIN, G.T. \& MCKEE, J.E. (1999) "Linking corporate entrepreneurship to strategy, structure and process", Entrepreneurship: Theory and Practice, 23(3): 85.

4 GEISLER, E. (1993) "Middle managers as internal corporate entrepreneurs", Interface, 23(6): 52-63.

5 HAIR, J.F; ANDERSON, R.E.; TATHAM, R.L. \& BLACK, W.C. (1998) Multivariate Data Analysis, (5 $5^{\text {th }}$ ed.) Prentice Hall: Englewood Cliffs, New Jersey.
6 HISRICH, R.D. \& PETERS, M.P. (1998) Entrepreneurship, (4 ${ }^{\text {th }}$ ed.) Irwin McGraw Hill: Boston.

7 HORNSBY, J.S.; NAFFZIGER, D.W.; KURATKO, D.F. \& MONTAGNO, R.V. (1993)

"An interactive model of the corporate entrepreneurship process", Entrepreneurship: Theory and Practice, 17(2): 29-40.

8 KURATKO, D.F.; MONTAGNO, R.V. \& HORNSBY, J.S. (1990) "Developing an intrapreneurial assessment instrument for an effective corporate entrepreneurial environment", Strategic Management Journal, 11: 49-58.

9 LUMPKIN, G.T. \& DESS, D.L. (1996) "Clarifying the entrepreneurial orientation construct and linking it to performance", Academy of management Review, 21(1): 35-172.

10 MORRIS, M.H. \& KURATKO, D.F. (2002) Corporate Entrepreneurship, Harcourt College Publishers: Florida.

11 PINCHOT, G. (1985) Intrapreneuring: Why You Don't Have to Leave the Corporation to be an Entrepreneur, Harper \& Row Publishers: New York.

12 RUSSEL, R.D. \& RUSSEL, C.J. (1992) “An examination of the effects of organisational norms, organisational structure, and environmental uncertainty on entrepreneurial strategy", Journal of Management, 18(4): 63953.

13 SELVIN, D.P. \& COVIN, J.G. (1990) "Juggling the entrepreneurial style and organisational structure", Sloan Management Review, 31(Winter): 43-5.

14 SHARMA, P. \& CHRISMAN, J.J. (1999) "Toward a reconciliation of the definitional issues in the field of corporate entrepreneurship", Entrepreneurship: Theory and Practice, 23(3): 11-28.

15 ZAHRA, S.A.; COVIN, J.G \& ZAHRA, P.H. (1998) "Organisational structure, corporate entrepreneurship and performance", Journal of enterprising Culture, 6(1): 111-46.

16 ZAHRA, S.A. \& PEARCE, J. (1989) "Board of directors and corporate financial performance: A review and integrative model", Journal of Management, 15: 291-344. 